\title{
Abuse in health care: a concept analysis
}

\author{
Adrianus Jelmer Brüggemann, Barbro Wijma and Katarina Swahnberg
}

\section{Linköping University Post Print}

N.B.: When citing this work, cite the original article.

This is the authors' version of the following article:

Adrianus Jelmer Brüggemann, Barbro Wijma and Katarina Swahnberg, Abuse in health care: a concept analysis, 2012, Scandinavian Journal of Caring Sciences, (26), 1, 123-132. which has been published in final form at:

http://dx.doi.org/10.1111/j.1471-6712.2011.00918.x

Copyright: Wiley-Blackwell http://eu.wiley.com/WileyCDA/Brand/id-35.html

Postprint available at: Linköping University Electronic Press http://urn.kb.se/resolve?urn=urn:nbn:se:liu:diva-75207 


\section{ABSTRACT}

Aims and objectives. To analyze the concept of abuse in health care. This analysis also covers how abuse in health care is different from the related concepts of medical error, patient satisfaction, and personal identity threat.

Background. Abuse in health care is an emerging concept in need of a clear analysis and definition. At the same time, boundaries to the related concepts are not demarcated.

Design. Concept analysis as developed by Walker and Avant.

Method. The databases Cumulative Index to Nursing and Allied Health Literature, Medline, and Google Scholar were used to obtain articles published between 1997 and 2009. A total of eleven articles are referred to on abuse in health care, four on medical error, six on patient satisfaction, and three on personal identity threat.

Results. Abuse in health care is defined by patients' subjective experiences of encounters with the health care system, characterized by devoid of care, where patients suffer and feel they lose their value as human beings. The events are most often unintended. We also found differences with the aforementioned related concepts: medical error does not share the patients' perspective and patient satisfaction does not offer room for patients' abusive experiences. The concept of personal identity threat shares all the attributes with abuse in health care, but it lacks an antecedent that signifies the social structures underlying the phenomenon.

Conclusions. Abuse in health care covers a phenomenon that has severe consequences, but is invisible if seen from a medical error or patient satisfaction perspective.

KEYWORDS: abuse in health care, concept analysis, medical error, patient satisfaction, Walker and Avant 


\section{INTRODUCTION}

Patient safety has received growing attention (1), and the prevention of medical errors stands high on the medical-political agenda (2). From clinical experiences, however, it has been noted that even medically correct health care encounters can have unwanted consequences for patients. This was first noted in female patients with a history of physical and sexual abuse $(3,4)$. Some years later this phenomenon was studied in a large project on violence in the Nordic countries and was labeled abuse in health care (AHC) (5).

Prevalence numbers and the consequences of $\mathrm{AHC}$ emphasize the urgency of understanding the phenomenon. Lifetime prevalence of $\mathrm{AHC}$ in the Nordic countries has been estimated to range between 13 and 28 percent for gynecology patients ( $n=3,641)$, and 8 to 20 percent of all patients reported that they are currently suffering from these experiences (6). Corresponding prevalence among Swedish men was about 7 percent, and 4 percent of the total sample reported current suffering (7).

\section{Aims}

Research on AHC is a growing field, but it lacks a clear conceptual definition that is applicable in research and clinical practice. Therefore, this study focused on a concept analysis, aiming to define AHC. Since it is a rather new concept that relates to established concepts, we also aimed to clarify how AHC is different from these concepts and where they overlap. We selected the concepts that we noticed are often confused with AHC: "medical error", "patient satisfaction" and "personal identity threat". A clear definition is a must, not only for pedagogical ends, but also in order to design successful interventions. Such interventions can only be successful if based on detailed knowledge of all elements of the concept. For this reason we aimed to analyze $A H C$ as a specific concept, rather than analyzing abuse in 
general; "in health care" does not merely indicate the location of the abuse but includes a structural setting, with predefined rules, roles, and dependencies.

\section{METHOD}

\section{Design}

According to the criteria set by Morse et al. (8), AHC is a so called "immature" concept; the concept definition lacks clarity and the concept boundaries are unknown. Moreover, as the volume of literature on the concept is limited, a form of concept development derived from the work of Wilson (9) should be preferred (8). The method by Walker and Avant (10) is one such Wilsonian method and was used for this analysis, as it provided a systematic approach to analyze relatively new concepts. In anticipation of critique on this method, we adapted a few of the original steps (box 1).

Concept analysis enables researchers to clarify a concept and is one building block in the theory building process. Through systematic analysis of scientific literature and cases, the main characteristics of the construct can be synthesized into a theoretical definition, that is "precise, understandable to others, and appropriate for the context in which the term will be used" $(11$, p. 242) The analysis of a new and immature concept that is not yet grounded in a pre-existing theory can therefore be an important step towards theory development (10), one of our predominant aims.

\footnotetext{
***box 1 near here***
}

\section{Data collection}


For AHC, we used the terms "abuse(d) in health care" and "abuse(d) in the health care system" when searching CINAHL, PubMed and Google Scholar for articles ranging from 1997 to 2009 (June). We only included research on patients abused in the health care system. The Swedish equivalent for AHC (kränkningar i vården) was also searched for in article titles and abstracts in these databases.

For the related concepts, analyses of each concept as an end or at least as a significant aim in the study were searched for in CINAHL, PubMed, and Google Scholar, also for publications ranging from 1997 to 2009 (June). We searched for the following terms: medical error ("medical error", "medical mistake", "health care errors", "hospital adverse event", "patient safety"), patient satisfaction ("patient satisfaction", "consumer satisfaction in health care", "patient dissatisfaction"), and personal identity threat ("personal identity threat"). To limit our search results, all searches were combined with "concept analysis", "concept", "defining", "definition", or "what is". If an article title seemed to fit our criteria we first read the abstract, followed by the whole text. We included data according to the standard order in which the search results appeared in the databases, i.e. according to relevance (Google Scholar, CINAHL) or date (PubMed). We stopped including articles as soon as we reached saturation, i.e. when we noticed repeating data.

\section{Material}

We found nine internationally published articles, one Swedish report, and one book section on the concept, which were all included in the analysis. A total of 13 articles on related concepts were included: four on medical error, six on patient satisfaction, and three on personal identity threat (box 2). 
To find cases to use in the analysis we had access to data from the Violations of Ethical Principles Questionnaire and from transcriptions of qualitative interviews with staff from a Women's clinic in south Sweden on their perceptions of AHC. These two data collections have been described elsewhere $(12,13)$.

***box 2 near here***

\section{Ethical considerations}

Both data collections of which we used case material in the analysis have been approved by the Regional Ethical Review board in Linköping. To ensure that no patients could be identified from the case descriptions we made changes in personal or circumstantial details.

\section{RESULTS}

\section{Uses of the concept AHC}

AHC cannot be found in any dictionaries, but as a starting point we looked at a dictionary definition of abuse in general. Abuse is used when "when someone uses or treats someone or something wrongly or badly, especially in a way that is to their own advantage" (14). Abuse of something can take place in health care in the form of substance abuse, but we continue looking at the abuse of someone.

AHC was first studied in the NorVold Abuse Questionnaire (NorAQ) and was operationalized by three questions (box 3). These operationalizations in NorAQ have been used in later studies as well $(6,7,13,15,16)$.

$* * *$ box 3 near here $* * *$ 
The concept of AHC has been used and defined in different ways and in all these definitions the patient's subjective experience is central $(16,17)$. One operationalization of $\mathrm{AHC}$, based on the ethical principles that guide Swedish health care, revealed that the concept entails different types of abuse: emotional, sexual, and physical abuse (13). The concept does not specify any means of abuse, as abuse can be verbal and non-verbal $(13,18)$, and it may take place in both childhood and adulthood $(6,7)$. In these studies, the direct victims of AHC were exclusively patients and AHC did not necessarily entail intentional harm.

\section{Determine the defining attributes}

Finding the critical attributes of $\mathrm{AHC}$ is an important step towards clarification of what the concept implies. Attributes are defined as characteristics that constantly appear in relation to the central phenomenon, even when seen from different perspectives (10). The following attributes were identified after analysis of the articles about AHC, and were simultaneously refined and tested by analysis of the cases and the related concepts (presented below). Note that all attributes must occur before a phenomenon can be labeled AHC.

1. Patients feel they lose their value as a human being

Qualitative studies with male and female patients showed one important overlapping result, namely that patients felt they lost their value as humans. The emotional responses to these feelings were different for men and women, however. During AHC, women felt "nullified" 
and bottled their strong emotions, while men felt "mentally pinioned" and expressed their frustrations $(16,17)$.

2. Patients suffer

Suffering is present as an attribute of $\mathrm{AHC}$ in all qualitative reports by patients $(16,17)$, and it is also part of most quantitative material as it is included in the operationalization in box 3 . Suffering can take many forms, but in all studies it has been described as something beyond a patient's disease or complaints, defined from the patient's subjective experience.

3. Most often an unintentional event

AHC has been described as a normal event which, without staff having any intention of causing harm or taking advantage, turned out abusive for the patient (19); in other words, it is often an unforeseen or at least an unintentional event. Röndahl mentions examples of standard paper documents that offended homosexual patients by assuming heterosexuality (18), which clearly lack any direct intentions. AHC can also involve intentional harm (see box 3, severe), which is likely to increase patient suffering. A characteristic (intent) that is most often lacking may be an odd kind of attribute. However, the possible lack of intention is distinct for $\mathrm{AHC}$ as it differentiates $\mathrm{AHC}$ from dictionary definitions of abuse as it most often does not benefit anyone, and therefore is important to emphasize.

4. Uncaring encounter

Carelessness was one category in a qualitative study on female patients' experiences of AHC (16). Here it should be emphasized that this attribute does not only stand for uncaring behavior from staff to patient. Cultural and structural elements in the encounter can also be uncaring; the abovementioned documents harmed homosexual patients without any staff being directly involved. 


\section{Model cases}

"A model case is an example of the use of the concept that demonstrates all the defining attributes of the concept" $(10$, p. 69). We included two model cases.

From the Violations of Ethical Principles questionnaire (translated from Swedish), female patient:

"The most terrible thing I ever experienced in health care was a doctor who threw a stethoscope on the ground and yelled at me to pick it up. While picking it up he yelled at me "you do not have back pains" and started to dictate journal notes in his tape recorder, stating that "the patient is simulating pain". I had much, much pain in my back and felt terrible by the abuse of being mistrusted and that the doctor did not talk to me but to his tape recorder instead. I have avoided doctors ever since. Horrible."

From the Violations of Ethical Principles questionnaire (translated from Swedish), male patient:

"1994, the 9th of August. I was accompanied by a medical student at a prostate examination. I got to wait outside the examination room. The medical student went in and I was left sitting in the corridor. She was oblivious to the fact that I heard how she described my appearance and particularly mentioned my large ears. When they were done laughing I was allowed to come into the room and was really laughed at. It surprised me that the physician did not react, but took part in the spectacle instead. For me it was embarrassing."

\section{Borderline, related, and contrary cases}


The defining attributes were refined, tested and teased by analyzing additional cases that share some or none of the attributes with AHC. This way it became clear what defining attributes counted for the concept of $A H C$ and which did not (10).

Borderline case based on an interview with a Swedish woman (translated from Swedish, paraphrased, data analyzed in (12).

A woman visited a Swedish hospital with her 13 year-old son who needed surgery. They had to stay at the hospital for about one week. Immediately upon entering the ward, the woman did not sense any compassion and staff did not talk much. Although a few members of staff made her feel happy, most were utterly neutral in their approach. She found it dreary and felt like a "pain in the ass". They received great help with the surgery, technically speaking, but the whole experience was unpleasant. She liked the receptionist at the ward who was the only one she could talk to. And there was one auxiliary nurse who gave that little bit of extra attention to her son; talked to him and asked him all kinds of questions. But besides the auxiliary nurse, all staff had the same uncompassionate attitude, which made the woman wonder if there was something wrong with her, or if she was looking sulky. She did not know.

This is a borderline case because it contains many, but not all, of the attributes of AHC. The encounter can be seen as unintentional and uncaring. But care is shown by some staff members who pay extra attention to the woman and her son. In this case, no medical mistake had been made, and the woman (as a patient/guardian representing the patient) gave no indication that she suffered a loss of her human value. There is no indication of suffering, so this phenomenon is rather characterized by a feeling of dissatisfaction. 
Related case (personal communication, male patient, paraphrased)

During a week's vacation, a 19 year old man gets itchy vesicles on his lower back. After his vacation he decides to visit his general practitioner (GP). The man informs the GP that, during his vacation, he shared a tent with someone who suffered from an impetigo infection. The GP looks at the spot and diagnoses eczema, with an alternative diagnosis of impetigo, which she, however, finds unlikely. She prescribes the man a corticosteroid and tells him to use it at least for one week. During that week the spots spread over the right side of his body, and every scratch he gets turns into a pustular sore. After a week half his body is covered with sores. Next visit to the GP results in a referral to a dermatologist, who diagnoses impetigo. The man feels both relief and anger, and wonders why his GP took a chance with eczema while the alternative diagnosis was of a highly contagious infectious disease.

This is a related case because it only shares a few of the attributes of $\mathrm{AHC}$, but it may still be confused with the phenomenon. The event clearly took place in health care, it was unintentional, and the patient suffered from the experience. However, the man does not seem to have lost his value as a human being, and the encounter can hardly be seen as uncaring. A more accurate term for what happened in this case is medical error.

Contrary case (18, p. 24), female homosexual patient (translated from Swedish)

"There was an auxiliary nurse that came in and immediately understood who I was and treated us as a couple from the first moment... and it felt really comforting that there was someone who saw me and understood us... she grasped us directly." 
This is a contrary case because it does not include any of the attributes of AHC; the patient felt respected as a human being and felt understood by the staff. Moreover, she did not suffer; instead she felt comforted and cared for.

\section{Related concepts}

From the beginning we selected three concepts that we noticed were related to and confused with AHC: medical error, patient satisfaction, and personal identity threat. The aim of this part of the analysis is to border AHC to these concepts.

\section{Medical error, patient satisfaction, and personal identity threat}

A momentous work on medical error was a report published by the Institute of Medicine titled To Err is Human (2). The report defined an error as "the failure of a planned action to be completed as intended or the use of a wrong plan to achieve an aim" $(2$, p. 4). Others, instead, argue for a focus on failures of an extent that could possibly harm the patient (20). Grober and Bohnen (21) include both omissions and a relation to a possible outcome in their definition. It is emphasized that errors are not merely human, but are to a large degree nurtured or caused by organizational factors. According to some authors there is too much focus on human failure instead of on a larger picture that includes procedures and environment (22).

The strongest contrast between $\mathrm{AHC}$ and a medical error lies in the perspective that defines the event. Medical error is based on the caregiver's perspective that defines whether or not something went wrong. While some of the attributes of AHC can be present in a medical error (patients suffer and lose their value as a human being), this is not 
necessarily the case. Therefore, certain events can be identified as both a medical error and AHC, as they can exist as parallels, emphasizing different elements in that event.

The measurement of patient satisfaction has become a popular instrument for making health care practice more people-centered, while a theoretical foundation appears to be missing (23). Hills and Kitchen define patient satisfaction as "a sense of contentedness, achievement or fulfillment that results from meeting patients' needs and expectations with respect to specific and general aspects of health care" (24, p. 245). Various definitions can be found, but there is a lack of agreement, leading to the concept being relative (25). For measuring satisfaction, patients are most often asked to fill out a questionnaire with a battery of Likert-scale items $(26,27)$. A problem with the concept of patient satisfaction is that it does not seem to capture patients' dissatisfaction appropriately (28).

While patient satisfaction and AHC share a patient perspective, AHC seems to catch more negative experiences. Experiences of suffering and losing one's value as a human being remain outside the scope of patient satisfaction surveys. These surveys usually cover many of the aspects of care received and aim to get an impression of patients' perceptions. AHC, on the other hand, is defined out of a single event or a number of consecutive events. AHC could contribute to lower patient satisfaction and may exist parallel to it, but low patient satisfaction does not necessarily imply AHC.

To better capture the concept of dissatisfaction, a Scottish research group decided to investigate this concept more deeply (29). In a qualitative study on what it means for a patient to be dissatisfied, the concept of personal identity threat emerged as a core category (30). This category stands for "the extent of humanity in health care", as it embraces the following sub-categories: dehumanized, objectified, stereotyped, disempowered, and devalued $(30$, p. $107 ; 118)$. These findings were later translated into a 
survey of person-centeredness in secondary care (31). More recent publications have not been found and no concept analyses have been done.

Personal identity threat shares all the attributes of AHC. Similar categories emerged from qualitative interviews as patients told about their negative experiences in health care, especially of feeling dehumanized. However, there is a difference between the research perspectives underlying the concepts; this concerns the antecedents and will be discussed below.

\section{Antecedents and consequences}

According to Walker and Avant (10), antecedents are the events or incidents that must be present before the concept occurs. Consequences are the events or incidents that may occur as a result of the concept. We added risk factors for $\mathrm{AHC}$ to the analysis as potential antecedents, a choice of expanding the model of analysis supported by Prof. L.O. Walker (personal communication, November 9, 2009).

Little is known about mechanisms leading to AHC, hence is it hard to identify antecedents. Even though no causal relationship is present, one antecedent is contact between a patient and any type of health care setting (15). Another essential non-causal antecedent is a patient's capacity to suffer and a view of himself or herself as a valuable human being. The latter, however, may not apply to patients who enter health care with no sense of self-worth, for example as seen in patients suffering from the consequences of severe abuse (outside health care) (32). For these patients, AHC may confirm their poor selfimage, and they may feel completely ruined and feel "less than worthless".

Certain patient characteristics may contribute to the risk of being abused in health care and are potential antecedents: childhood abuse outside health care, young age, 
high educational level (15), and poor self-rated health (6). A study on male patients showed higher risk for $\mathrm{AHC}$ in those who were born in a foreign country (7). Hierarchies, rules, power asymmetries, and taboos contribute to or even legitimize the occurrence of $\operatorname{AHC}(13,16,33$, 34). It is this structural perspective that differentiates AHC from personal identity threat. In the survey of person-centeredness in secondary care, based on personal identity threat, only the staff's behavior is evaluated (31). The concept of AHC is broader and can also include events where no staff is involved, signifying the underlying structures in health care encounters. Inherent to this structural perspective is that very little is known about staff's behavior as an antecedent for AHC.

Consequences have been identified, for:

\section{Patients}

Case studies have shown that patients can experience ill-health as a consequence of AHC (33). For example, strong associations with $\mathrm{AHC}$ have been found with post-traumatic stress symptoms (6). Avoidance of the health care system has been noticed in qualitative studies with both men and women $(16,17)$. Women reported suffering up to many years after the event had taken place (16).

2. Staff

Having been involved in cases of AHC, especially in the concealment of abuse and allowing it to take place, staff often suffered from feelings of guilt and shame as a consequence (34).

3. Health care system

From qualitative studies it appeared that men who experienced $\mathrm{AHC}$ lost their confidence in the health care system, which was one reason for them not to leave a formal complaint (17). 


\footnotetext{
$* * *$ Figure 1 near here***

$* * *$ Figure 2 near here ${ }^{* * *}$
}

\section{Empirical referents}

Empirical referents are those categories that enable us to measure and recognize a clinically relevant phenomenon in research and in practice. For AHC, little knowledge exists. In questionnaires, questions as presented in box 3 are used to identify AHC, and asked directly to patients. In one questionnaire, staff working at a Swedish women's clinic were asked to describe cases of $\mathrm{AHC}$ and how they recognized the patients' suffering. For example, staff mentioned the following: a patient tells or writes about it, says she feels abused, cries, shows a certain facial expression, is tensed in the body, feels worried and sad, or is (unusually) silent (unpublished material). The empirical referents are very diverse and diffuse; they range from very explicit to almost invisible, and more research is needed.

\section{Definition of AHC}

Based on the analysis of the concept of AHC, the following definition can be formulated.

Abuse in health care is defined from patients' subjective experiences of encounters with the health care system, characterized by events that lack care, where patients suffer and feel they lose their value as human beings. The events are most often unintentional and nurtured and legitimized by the structural and cultural contexts in which the encounter takes place. The outcomes of abuse in health care are negative for patients and presumably for staff and the health care system as well. 


\section{DISCUSSION AND PRACTICAL IMPLICATIONS}

As research about AHC developed and clinical interventions became more widespread, we noticed an urge for conceptual clarification and systematization of AHC. As a method of concept analysis we chose the model developed by Walker and Avant (10), which is sometimes presented as positivistic, rigid and reductionist $(35,36)$. Considering form, the method appears to be a strict pattern to follow. The step-by-step method does contain guidelines to structure and present findings in a logical manner, but the structure of the method greatly differs from the iterative and circular form that the analysis takes. The fact that its content is based on apparently positivist and reductionist assumptions is recognized by Walker and Avant (10). They emphasize explicitly, in contrast to what Weaver and Mitcham claim (35), that concepts change over time and that a concept analysis is never a "finished product". They state that this tentativeness is further increased by the fact that no two researchers would get the same results analyzing a concept. With these comments, Walker and Avant put themselves in line with our own view of knowledge as tentative and situated.

Situated knowledge (37) is an inevitable part of us being interpreting humans and researchers. We can, however, make our position more transparent by recognizing our perspectives and emphasize openness. In this analysis we explicitly tried to make our thoughts and interpretations visible, and thus our pre-understanding of the field and the concept. We expect this to have increased the potential repetitiveness of the analysis and thereby its reliability, even though repetition will not necessarily give identical results because of reasons described above. Also, the cases included in the analysis are not constructed; they are empirical and represent views on the concept of AHC from different perspectives. Our interpretations of these cases are also situated, but as they are first-hand 
empirical cases, this is the closest we can come as researchers. By including these empirical cases and emphasizing transparency, we could present data and analysis side by side, not losing the patients' voice. Health care staff's knowledge is also situated when interpreting a patient encounter, which emphasizes the importance of more detailed knowledge about AHC, not the least on empirical referents. If, for example, patients do not express their suffering verbatim they may send other signals that staff need to recognize in order to understand the situation.

Even though a variation of cases was included, it should be noted that the diversity of perspectives is limited, as the phenomenon has only been studied in the Nordic countries. In the qualitative study with male patients, however, native country was included as a variable for the procedure of theoretical sampling to capture the cultural sensitivity of the concept (17), as a quantitative study had shown that being born in a foreign country increased the risk for AHC in male patients (7). The theory generated in the qualitative study, which has been central in this concept analysis, thereby captured experiences from patients with different cultural backgrounds. This "cultural competency" (38) within a Nordic setting, is a strength of the concept. Another limitation of the material included is that all but one of the articles on AHC come from one research group. This was not due to a choice of articles but was a consequence of our focus on a specific concept, with specific search terms. As stated in the introduction, we chose to analyze AHC as a specific concept, considering that a growing research field centers around it and a definition was lacking. A strength of the included material is that it covers qualitative and quantitative research involving both men and women.

The present analysis resulted in a theoretical definition of the concept of AHC. Another result was that $\mathrm{AHC}$ is different from medical error, patient satisfaction, and 
personal identity threat. With medico-political focus on preventing medical errors and increasing patient satisfaction, $\mathrm{AHC}$ remains largely invisible. Considering the consequences of $\mathrm{AHC}$ this invisibility is an ethical challenge for the health care system. Interventions to prevent and better deal with AHC could benefit from the results of the analysis and the detailed definition of AHC. It would also be worthwhile to study the concept of personal identity threat more closely. What can be learnt from this related concept? How has research on that concept been implemented in clinical environments? On a theoretical level, AHC could benefit from being included in a larger framework; further theorization could help the concept develop and become recognized in a larger research and clinical context. This concept analysis should be seen as a first step in that direction.

Despite being part of a theorization process, are there any ways this concept analysis can aid health care staff in acting against AHC? No absolute strategies can directly be formulated from the results of this analysis, but the following means may be suggested from figure 1. First, by preventing possible events and becoming aware of the (potential) antecedents. Besides being an organizational issue, health care staff has the possibility and professional responsibility of reporting $\mathrm{AHC}$ to the clinical management and ask for the support needed. There is also a need for staff to be trained in how to better recognize and care for the needs of patients with a background of childhood abuse, as these patients risk to be revictimized in health care (15). Here it should be noted that the patient characteristics labeled as potential antecedents should not entail any patient responsibility; these factors rather should inform staff and the system about where extra attention is needed. Second, by dealing with $\mathrm{AHC}$ while it is happening, through recognition of the empirical referents. Here, more research must be done on identifying empirical referents. Third, by coping with bad consequences, specifically relieving patients' and staff's suffering. According to Eriksson (39), 
alleviating patients' suffering is central to caring, and is motivated by an unconditional love or caritas (40). Alleviating suffering can only begin if the patient's suffering is seen and confirmed by staff, and can be expressed in the encounter between patient and staff (39, 41). As Rehnsfeldt and Eriksson conclude, if the patient is not invited to such an encounter, there is a risk that the patient's suffering will not be alleviated (41). With regard to staff's suffering, their feelings of shame and guilt could lead to concealment, which makes the abusive event a hidden memory. Concealment may therefore hamper staff from learning from the event and increase the risk that it happens again (34). The current analysis gives a clear definition of AHC that should make it possible for staff to talk more openly among colleagues about these often invisible phenomena.

\section{CONCLUSION}

By using the method of concept analysis by Walker and Avant we provided an analysis and a theoretical definition of $A H C$, which should enhance understanding of the phenomenon in research and clinical practice. AHC covers a health care phenomenon with negative consequences for patients and possibly even for staff and the health care system. Our analysis also showed that $A H C$ is largely invisible if studied from a patient satisfaction or medical error perspective. 


\section{REFERENCES}

World Health Organization. World alliance for patient safety: forward programme. 2004, Geneva. system. 2000, National Academy Press, Washington, D.C.

Publications Ltd, London.

Jehu D. Beyond sexual abuse. Therapy with women who were childhood victims. 1988, John Wiley \& Sons, Avon.

5 Swahnberg K, Wijma B. The NorVold Abuse Questionnaire (NorAQ): validation of new measures of emotional, physical, and sexual abuse, and abuse in the health care system among women. Eur J Public Health 2003; 13:361-6.

6

Swahnberg K, Schei B, Hilden M, Halmesmaki E, Sidenius K, Steingrimsdottir T, et al. Patients' experiences of abuse in health care: a Nordic study on prevalence and associated factors in gynecological patients. Acta Obstet Gynecol Scand 2007; 86:349-56.

7 Swahnberg K, Hearn J, Wijma B. Prevalence of perceived experiences of emotional, physical, sexual, and health care abuse in a Swedish male patient sample. Violence Vict 2009; 24:265-79.

8

Morse JM, Mitcham C, Hupcey JE, Tason MC. Criteria for concept evaluation. J Adv Nurs 1996; 24:385-90.

$9 \quad$ Wilson J. Thinking with concepts. 1963, Cambridge Univ Pr, New York.

Walker LO, Avant KC. Strategies for theory construction in nursing. 4th ed.

2005, Pearson Prentice Hall, New Jersey. 
design in nursing research (Brink PJ, Wood MJ eds.), 1998 Sage, New Delhi, 235-82. in health care. J Psychosom Obstet Gynaecol 2010; 31:123-9. disobedience of ethical principles. Acta Obstet Gynecol Scand 2006; 85:830-6. Cambridge Advanced Learner's Dictionary. Retrieved from http://dictionary.cambridge.org/ on 3 June 2009. 2009. experiences of abuse in the health care system: their relationship to childhood abuse. BJOG $2004 ; 111: 1429-36$. being abused in health care. J Psychosom Obstet Gynaecol 2007; 28:161-7. pinioned: men's perceptions of being abused in health care. Int J Mens Health 2009; 8:60-71. 18 Röndahl G. Homosexuella patienter och närståendes upplevelser i vården [Experiences in health care by homosexual patients and their close ones]. 2004, HoMo. Retrieved from http://www.homo.se/upload/homo/pdf homo/Uppsats GRondahl.pdf on 8 January 2010. sociodemographic and regional and sample factors associated with prevalence of abuse? Acta Obstet Gynecol Scand 2004; 83:276-88. 
37:1043-51.

23 Turris SA. Unpacking the concept of patient satisfaction: a feminist analysis. J Adv Nurs 2005; 50:293-8.

24 Hills R, Kitchen S. Toward a theory of patient satisfaction with physiotherapy: exploring the concept of satisfaction. Physiother Theory Pract 2007; 23:243-54.

25 Gill L, White L. A critical review of patient satisfaction. Leadersh Health Serv 2009; 22:8-19.

26 Yellen E, Davis GC, Ricard R. The measurement of patient satisfaction. J Nurs Care Qual 2002; 16:23-9.

27 Merkouris A, Ifantopoulos J, Lanara V, Lemonidou C. Patient satisfaction: a key concept for evaluating and improving nursing services. J Nurs Manag 1999; 7:19-28. Med 1997; 45:1829-43.

D. The meaning of patient satisfaction: an explanation of high reported levels. Soc Sci Med 1998; 47:1351-9. importance of 'personal identity threat'. Sociol Health IIIn 1999; 21:95-123. instrument through a survey of person-centredness in secondary care. J Adv Nurs 2001; 36:450-9. 
nurtured by concealment: a clinical report. J Psychosom Obstet Gynaecol 2007; 28:155-60.

Wijma B, Swahnberg K. Stories never told - How concealment nurtures violence. In: Gender delight : science, knowledge, culture, and writing ... : for Nina Lykke (Åsberg C, Harrison K, Pernrud B, Gustavson M eds.), 2009 Tema Genus, Linköping. art. Nurs Philos 2008; 9:180-94. paper which explores and critiques the ontological focus, reliability and antecedents of concept analysis frameworks. Int J Nurs Stud 2008; 45:1831-41. Privilege of Partial Perspective. Fem Stud 1988; 14:575-99. cultural competency concepts? Teaching and Learning in Nursing 2011; 6:84-8. hope (Gaut D, Boykin A eds.), 1994 National League for Nursing Press, New York, NY, 3-20. suffering. Scand J Caring Sci 2004; 18:264-72. analysis: a critique. Sch Inq Nursing Pract 1996; 10:185. 

concept of patient dissatisfaction in the light of patient satisfaction research. Leadersh Health Serv 1999; 12:1-9. 


\begin{tabular}{|c|c|c|}
\hline Original steps & Adapted steps & Explanation \\
\hline 1. Select a concept & - & $\begin{array}{l}\text { "choose a concept that is important and useful to your research } \\
\text { program or to further theoretical developments in your area of } \\
\text { interest" (p. 66) }\end{array}$ \\
\hline $\begin{array}{l}\text { 2. Determine the } \\
\text { aims of analysis }\end{array}$ & - & $\begin{array}{l}\text { "focus attention on exactly what use you intend to make of the } \\
\text { results of your effort" (p. } 66 \text { ) }\end{array}$ \\
\hline $\begin{array}{l}\text { 3. Identify all uses } \\
\text { of the concept } \\
\text { (using dictionaries, } \\
\text { thesauruses, } \\
\text { colleagues, and } \\
\text { available } \\
\text { literature) }\end{array}$ & - & $\begin{array}{l}\text { "identify as many uses of the concept as you can find" (p. 67), "this } \\
\text { review of literature helps you support or validate your ultimate } \\
\text { choices of the defining attributes" (p. 67) }\end{array}$ \\
\hline $\begin{array}{l}\text { 4. Determine the } \\
\text { defining attributes }\end{array}$ & - & $\begin{array}{l}\text { "the effort is to try to show the cluster of attributes that are the } \\
\text { most frequently associated with the concept and that allow the } \\
\text { analyst the broadest insight into the concept" (p. 68) }\end{array}$ \\
\hline $\begin{array}{l}\text { 5. Identify a model } \\
\text { case }\end{array}$ & $\begin{array}{l}\text { Identify multiple } \\
\text { model cases from } \\
\text { different (social) } \\
\text { perspectives }\end{array}$ & $\begin{array}{l}\text { "a model case is an example of the use of the concept that } \\
\text { demonstrates all the defining attributes of the concept" (p. 69), } \\
\text { multiple models from different perspectives assists in capturing the } \\
\text { wide social construction of the concept (42) }\end{array}$ \\
\hline \multirow[t]{2}{*}{$\begin{array}{l}\text { 6. Identify } \\
\text { borderline, } \\
\text { related, contrary, } \\
\text { invented, and } \\
\text { illegitimate cases }\end{array}$} & $\begin{array}{l}\text { Identify } \\
\text { borderline, } \\
\text { related, and } \\
\text { contrary cases }\end{array}$ & $\begin{array}{l}\text { "The basis purpose for these cases is to help you decide what } \\
\text { "counts" as a defining attribute for the concept of interest and what } \\
\text { doesn't count" (p. 70) Invented cases reduce validity of the analysis } \\
\text { and are excluded (43). Illegitimate cases are not necessary if the } \\
\text { concept is not commonplace (10). }\end{array}$ \\
\hline & $\begin{array}{l}\text { Identify and } \\
\text { define related } \\
\text { concepts that } \\
\text { share some } \\
\text { attributes with the } \\
\text { concept being } \\
\text { studied }\end{array}$ & $\begin{array}{l}\text { "Wilsonian-derived methods target the use of a concept across } \\
\text { contexts with less emphasis on the internal consistency (e.g. [...] } \\
\text { well-defined boundaries with other concepts)" (35). This step } \\
\text { contrasts the studied concept with related concepts and } \\
\text { contributes in that way to more synergetic theory building, and the } \\
\text { development of the studied concept as a demarcated area in, e.g., } \\
\text { research. }\end{array}$ \\
\hline $\begin{array}{l}\text { 7. Identify } \\
\text { antecedents and } \\
\text { consequences }\end{array}$ & $\begin{array}{l}\text { In addition } \\
\text { identify potential } \\
\text { antecedents }\end{array}$ & $\begin{array}{l}\text { "[These steps] may shed considerable light on the social contexts in } \\
\text { which the concept is generally used" (p. 72). "Antecedents are } \\
\text { those events or incidents that must occur prior to the occurrence of } \\
\text { the concept" (p. 73). "Consequences, on the other hand, are those } \\
\text { events or incidents that occur as a result of the occurrence of the } \\
\text { concept" (p. 73) }\end{array}$ \\
\hline $\begin{array}{l}\text { 8. Define empirical } \\
\text { referents }\end{array}$ & - & $\begin{array}{l}\text { "Empirical referents are classes or categories of actual phenomena } \\
\text { that by their existence or presence demonstrate the occurrence of } \\
\text { the concept itself" (p. 73) "In many cases the defining attributes } \\
\text { and the empirical referents will be identical" (p. 73). When the } \\
\text { attributes are highly abstract, empirical referents are necessary. }\end{array}$ \\
\hline
\end{tabular}

Box 1: Summary of steps in Walker and Avant (10) with adapted steps. Cited explanations come from Walker and Avant (10) if not stated otherwise. Note that this method is iterative, not linear. 


\begin{tabular}{|c|c|c|}
\hline Concept & Reference & Title \\
\hline \multirow[t]{11}{*}{ Abuse in health care } & (18) & $\begin{array}{l}\text { Homosexuella patienter och närståendes upplevelser i vården (Swe: Experiences } \\
\text { in health care by homosexual patients and their close ones) }\end{array}$ \\
\hline & (5) & $\begin{array}{l}\text { The NorVold Abuse Questionnaire (NorAQ): validation of new measures of } \\
\text { emotional, physical, and sexual abuse, and abuse in the health care system } \\
\text { among women }\end{array}$ \\
\hline & (15) & $\begin{array}{l}\text { Women's perceived experiences of abuse in the health care system: Their } \\
\text { relationship to childhood abuse }\end{array}$ \\
\hline & (13) & Female patients report on health care staff's disobedience of ethical principles \\
\hline & (6) & $\begin{array}{l}\text { Patients' experiences of abuse in health care: a Nordic study on prevalence and } \\
\text { associated factors in gynecological patients }\end{array}$ \\
\hline & (16) & Nullified: women's perceptions of being abused in health care \\
\hline & (17) & Mentally pinioned: Men's perceptions of being abused in health care \\
\hline & $(32)$ & What is an error? \\
\hline & (33) & Cycles of abuse nurtured by concealment: a clinical report \\
\hline & (34) & Stories never told - How concealment nurtures violence \\
\hline & (7) & $\begin{array}{l}\text { Prevalence of perceived experiences of emotional, physical, sexual, and health } \\
\text { care abuse in a Swedish male patient sample }\end{array}$ \\
\hline \multirow[t]{4}{*}{ Medical error } & (2) & To err is human: Building a safer health system \\
\hline & (20) & What is an error? \\
\hline & $(22)$ & Medical errors: an introduction to concepts \\
\hline & (21) & Defining medical error \\
\hline \multirow[t]{6}{*}{ Patient satisfaction } & (28) & Patient satisfaction: a review of issues and concepts \\
\hline & (27) & Patient satisfaction: a key concept for evaluating and improving nursing services \\
\hline & (26) & The measurement of patient satisfaction \\
\hline & (23) & Unpacking the concept of patient satisfaction: a feminist analysis \\
\hline & (24) & $\begin{array}{l}\text { Toward a theory of patient satisfaction with physiotherapy: exploring the concept } \\
\text { of satisfaction }\end{array}$ \\
\hline & $(25)$ & A critical review of patient satisfaction \\
\hline \multirow[t]{3}{*}{ Personal identity threat } & (30) & $\begin{array}{l}\text { Exploring the Meaning of 'Dissatisfaction' with Health Care: The Importance of } \\
\text { 'Personal Identity Threat' }\end{array}$ \\
\hline & (44) & $\begin{array}{l}\text { Seeing the wood for the trees: defining the forgotten concept of patient } \\
\text { dissatisfaction in the light of patient satisfaction research }\end{array}$ \\
\hline & (31) & $\begin{array}{l}\text { Valuing people as individuals: development of an instrument through a survey of } \\
\text { person-centeredness in secondary care }\end{array}$ \\
\hline
\end{tabular}

Box 2: summary of the literature included for each concept 


\begin{tabular}{|c|c|}
\hline & Abuse in health care \\
\hline Mild abuse & $\begin{array}{l}\text { Have you ever felt offended or grossly degraded while visiting health care services, felt } \\
\text { that someone exercised blackmail against you or did not show respect for your opinion } \\
\text { - in such a way that you were later disturbed by or suffered from the experience? }\end{array}$ \\
\hline Moderate abuse & $\begin{array}{l}\text { Have you ever experienced that a "normal" event, while visiting health care services } \\
\text { suddenly became a really terrible and insulting experience, without you fully knowing } \\
\text { how this could happen? }\end{array}$ \\
\hline \multirow[t]{4}{*}{ Severe abuse } & $\begin{array}{l}\text { Have you ever experienced anybody in health service purposely - as you understood - } \\
\text { hurting you physically or mentally, grossly violating you or using your body and your } \\
\text { subordinated position to your disadvantage for his/her own purpose? }\end{array}$ \\
\hline & Answer alternatives (same for all questions) \\
\hline & $\begin{array}{l}1=\text { No, } 2 \text { = Yes, as a child ( }<18 \text { years), } 3=\text { Yes, as an adult ( } \geq 18 \text { years), } 4=\text { Yes, as a } \\
\text { child and as an adult. }\end{array}$ \\
\hline & AHC was operationalized as at least one Yes to one of the three questions. \\
\hline
\end{tabular}

Box 3: Questions about Abuse in Health Care in the Norvold Abuse Questionnaire 


\begin{tabular}{|l|l|l|l|}
\hline Antecedents \\
- Contact between patient and the \\
-Patient has the capacity to suffer
\end{tabular}

Figure 1: Overview of antecedents, attributes, and consequences of abuse in health care 


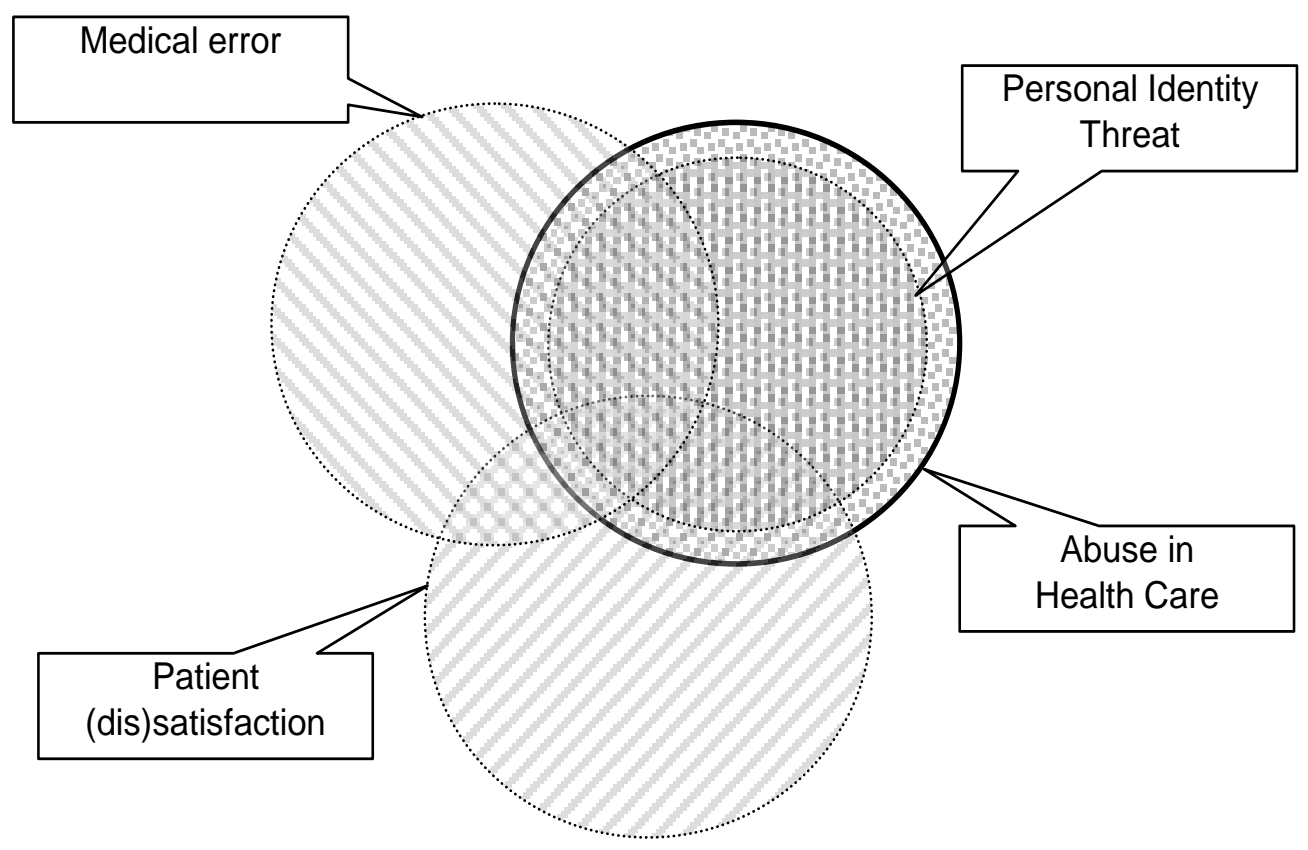

Figure 2: Abuse in health care in relation to other concepts. The circles cover different events that are identified by the concepts, where overlap represents the range of similar events covered. 